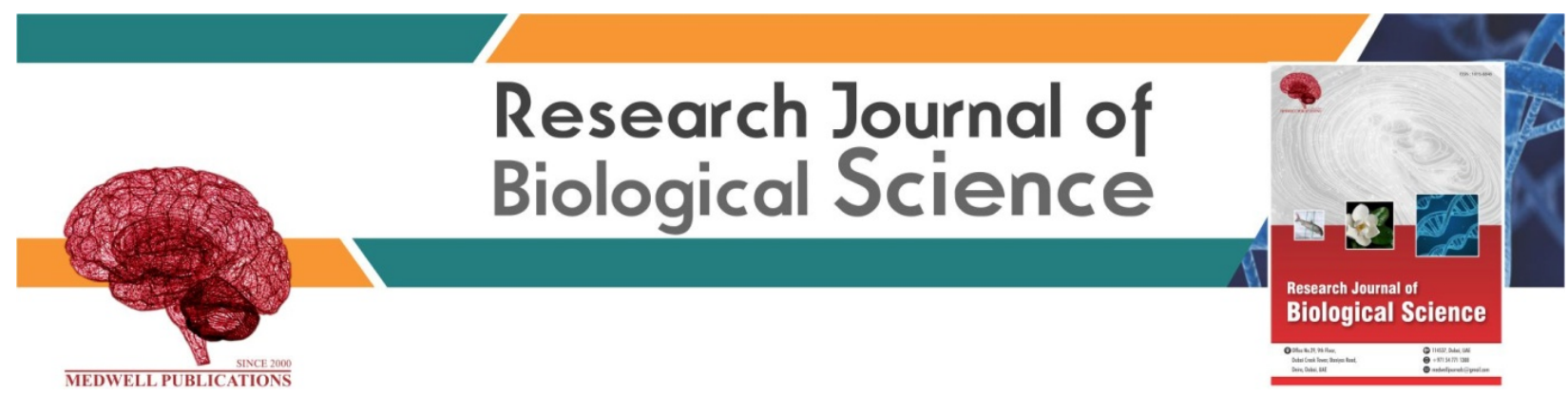

\title{
Mummy Enhances Chondrocyte Proliferation and the Expression of Extracellular Matrix Components in Monolayer and 3D Culture Conditions
}

${ }^{1}$ Fariba Rezaei, ${ }^{2}$ Maryam Hassan Famian, ${ }^{1}$ Hajar Shafaei, ${ }^{1}$ Jafar Soleimani Rad, ${ }^{1}$ Leila Roshangar and ${ }^{1}$ Azadeh Montaseri

${ }^{1}$ Stem Cell Research Center, Tabriz University of Medical Sciences, Tabriz, Iran

${ }^{2}$ Department of Molecular Biology, Islamic Azad University, Ahar Branch, Ahar, Iran

Key words: Osteoarthritis, chondrocytes, proliferation, gene expression, extracellular matrix

\section{Corresponding Author:}

Azadeh Montaseri

Department of Histology and Embryology, Stem Cell Research Center, Tabriz University of Medical Sciences, Tabriz, Iran

Page No.: 33-39

Volume: 15, Issue 2, 2020

ISSN: $1815-8846$

Research Journal of Biological Sciences

Copy Right: Medwell Publications
Abstract: To investigate the probable effects of mummy on chondrocyte proliferation and expression of cartilage specific gene. Chondrocytes at the second passage were plated at density of $1 \times 10^{6}$ in monolayer or seeded onto PCL scaffolds. Cells in both conditions were divided into control (received medium) or treated with mummy at concentrations of 500 or $1000 \mu \mathrm{g} \mathrm{mL}^{-1}$ for $72 \mathrm{~h}$. The gene expression profile of collagen II, aggrecan, Cartilage Oligomeric Matrix Protein (COMP) and Sox-9 was evaluated using real-time RT-PCR. The ability of mummy to enhance the proliferation of chondrocytes was further evaluated using doubling time. Treatment of chondrocytes with $1000 \mu \mathrm{g} \mathrm{mL}^{-1}$ of mummy resulted in a significant increase in expression of Sox-9, COMP and aggrecan genes in both monolayer and 3D culture conditions. Compared to the monolayer cultivated cells, expression of genes in seeded chondrocytes on PCL scaffolds was significantly higher. The highest proliferation rate of chondrocytes was found at a concentration of $1000 \mu \mathrm{g} \mathrm{mL}^{-1}$. The preliminary findings of this study revealed that mummy can be a promoting factor for chondrocyte proliferation and ECM synthesis. The use of mummy at $1000 \mu \mathrm{g} \mathrm{mL}^{-1}$ may be a suitable dose for cartilage tissue engineering.

\section{INTRODUCTION}

The rising prevalence of age-related diseases such as musculoskeletal system disorders seriously influences the health of millions of people worldwide. Among them, Osteoarthritis (OA) is the most common form of rheumatic disorders characterized by the progressive deterioration of the Cartilage Extracellular Matrix (ECM). It is a major cause of pain and disability in middle-aged and older people and a huge economic burden for healthcare systems around the world ${ }^{[1-3]}$.
This multifactorial degenerative joint disease has unknown etiology ${ }^{[4]}$. Different risk factors are involved in the progression of OA such as genetic predisposition, gender, trauma, aging, obesity and previous incidence of Rheumatoid Arthritis (RA). Among these, advancing age is known as the major factor ${ }^{[1,3]}$. At the molecular level, $\mathrm{OA}$ is characterized as an imbalance between ECM components synthesis and degradation which is controlled by chondrocytes in normal condition $\mathrm{S}^{[5,6,2]}$. Pro-Inflammatory cytokines such as interleukin (IL-1ß) and Tumor Necrosis Factor-alpha (TNF- $\alpha$ ) have a crucial 
role in articular cartilage destruction due to induction of cartilage degrading enzymes release such as Matrix Metalloproteinases (MMPs) ${ }^{[6,2]}$.

Current therapeutic methods for OA include oral or topical administration of Nonsteroidal Anti-Inflammatory Drugs (NSAIDs), steroids and opioids and also surgical procedures such as marrow stimulating techniques, mosaicplasty, microfracture and total joint arthroplasty ${ }^{[3]}$. These therapies are only palliative and surgical methods usually result in formation of fibrocartilage tissue with abnormal biochemical composition ${ }^{[5]}$.

Recently, there is a growing interest in the application of chondrocyte transplantation to restore damaged cartilage. As dedifferentiation of chondrocytes occurs in the culture conditions used leading to the formation of low quality newly formed tissue, advances in tissue engineering have introduced 3-D scaffolds where seeded chondrocytes can maintain their differentiated phenotype ${ }^{[7]}$. Another factor with potency for promotion of chondrogenesis and maintenance of chondrocyte phenotype is the use of a growth factor ${ }^{[8]}$. Different investigations have highlighted to the crucial function of growth factors in cartilage repair and production of ECM by chondrocytes in in vitro and in vivo conditions ${ }^{[9]}$. However, application of these factors has its limitations such as high cost, short half-life and fast degradation ${ }^{[10]}$ which encourages researchers to find and identify other enhancers with lower cost and prolonged activity. To address these issues, there is currently a great interest in using traditional medicine due to lower adverse effects, feasible access and its acceptance by a great number of people, especially, in developing countries ${ }^{[11]}$.

Several herbal compounds and nutraceuticals have been investigated as alternatives in the treatment of $\mathrm{OA}^{[12]}$. In Iranian traditional medicine, mummy or sweat mountain which is named mumnaye by local people is used routinely for treatment of bone fractures, joint inflammation, peptic ulcer and wound healing ${ }^{[13]}$. This pitch-like and semi-solid material which is dark brown to black in colour is obtained due to oil oxidation in cracks and fractures of the floors in some caves. Chemical analysis indicated the presence of hydrocarbons, calcium, phosphate, carbonate, magnesium, sulfur, oxygen, nitrogen and polysaccharides in mummy ${ }^{[11,13]}$. The advantageous effects of this material have been mentioned by Bu-Ali Sina (Avecina) in his Canon (Law) book. Due to its unknown effects in the past few years, some Iranian researchers investigated the effect of this material in different disorders such as fracture ${ }^{[11]}$, peptic ulcer ${ }^{[13]}$ and wound healing. Taking into account claims of indigenous people and Persian traditional medicine advice, the present study was designed to investigate whether mummy material can promote chondrocyte proliferation and expression of cartilage specific genes such as Sox-9, COMP, aggrecan and collagen II in a 3-Dimensional culture condition.

\section{MATERIALS AND METHODS}

Cartilage samples: Chondrocytes were isolated from human articular cartilage of middle-aged patients (50-76 years) undergoing total knee or hip replacement surgery. Cartilage was harvested from non-lesional areas. Immediately after the operations, the cartilage fragments were put in sterile conical tubes containing Phosphate Buffered Saline (PBS) supplemented with 1\% Penicillin/Streptomycin $(\mathrm{P} / \mathrm{S})$ and conveyed from the hospital to the cell culture lab. All patients gave written informed consent and the institutional review board and medical ethics committee of Tabriz University of Medical Sciences approved the study protocol.

Chondrocyte isolation and expansion: Upon receipt, cartilage samples were washed three times using PBS containing $1 \% \mathrm{P} / \mathrm{S}$. Then, samples were sliced into 1-2 mm thick pieces and washed extensively in PBS with $1 \% \mathrm{P} / \mathrm{S}$ to ensure sterility of the specimens prior to enzymatic digestion. In the next step, samples were digested initially with $1 \%$ pronase for $2 \mathrm{~h}$ at $37^{\circ} \mathrm{C}$ and subsequently with $0.2 \%(\mathrm{v} / \mathrm{v})$ collagenase type II for $4 \mathrm{~h}$ at $37^{\circ} \mathrm{C}$. After digestion, the collagenase was neutralized by adding $10 \%$ Fetal Bovine Serum (FBS) containing Dulbecco's Modified Eagle's Medium (DMEM). The cell suspension was then passed through a nylon filter mesh $(70 \mu \mathrm{m})$ to separate the chondrocytes from undigested particles. The filtered cell suspension was centrifuged at $1500 \mathrm{~g}$ for $5 \mathrm{~min}$ at $4^{\circ} \mathrm{C}$. The obtained cell pellet was washed three times in PBS or serum free medium. The cell viability was determined by trypan blue dye exclusion test. Chondrocytes were plated at $1 \times 10^{6}$ cells per T75 flask and incubated at $37^{\circ} \mathrm{C} / 5 \% \mathrm{CO}_{2}$. The first medium change was performed after $24 \mathrm{~h}$ and following medium changes three times per week. Upon reaching 70\% confluency, chondrocytes were passaged using trypsin/EDTA.

Preparation and anlaysis of mummy: The mummy material was purchased from the local market in Kermanshah, Iran and its quality was approved by a botanist. Because of the water-solubility of mummy, it was dissolved in DMEM without the addition of any other solvent. As this material has not been tested on cells in vitro previously, the effective concentration was obtained using the MTT assay. To understand the chemical ingredients in mummy, Gas-Chromatography-Mass Spectrometery (GC-MS) technique was performed.

MTT assay: This test is based on the ability of mitochondria of viable cells to convert soluble MTT (3-(4.5-dimethyl-2-thiazole)-2.5-diphenyl-2-yl-tetrazoli um bromide) into an insoluble purple formazan reaction product $^{[14]}$. Chondrocytes at third passage were seeded 
onto 96-well plates at a concentration of 2,000 cells per well suspended in DMEM containing 10\% FBS and incubated for $24 \mathrm{~h}$. The cells were incubated in serum-free medium as a control or treated with various concentrations (100-2000 $\mu \mathrm{g} \mathrm{mL}^{-1}$ ) of mummy for 24,48 and $72 \mathrm{~h}$. Then, $20 \mu \mathrm{L}$ of $10 \%$ MTT reagent solution $\left(5 \mathrm{mg} \mathrm{mL}^{-1}\right)$ diluted in PBS was added to each well. The cultures were immediately incubated for $4 \mathrm{~h}$ at $37^{\circ} \mathrm{C}$ and protected from light until the presence of the violet formazan crystals was observed. This is due to action of succinate-tetrazolium reductase belonging to mitochondrial respiratory chain.

For formazan crystals solubilization, the MTT solution was removed and $100 \mu \mathrm{L}$ of Dimethyl Sulfoxide (DMSO) was added to each well. The absorbance of the purple colored dissolved crystals was measured at a wavelength of $570 \mathrm{~nm}$ using an ELISA-reader (Tecan, $\mathrm{CH}-8708$, Australia). All experiments were performed in triplicate.

Proliferation rate assay: To quantify and compare the expansion rate of the cells, chondrocytes were cultivated in monolayer culture at a concentration of 50,000 cells/well in 6-well culture dishes suspended in DMEM supplemented with $10 \%$ FBS and $1 \% \mathrm{P} / \mathrm{S}$ and incubated for $24 \mathrm{~h}$. Thereafter, for evaluation of Mummy effects on chondrocyte proliferation rate, cells were treated with control and different Mummy concentrations for $72 \mathrm{~h}$. At the end of cultivation period, cell population Doubling Time (DT) was determined for the cultures using $\mathrm{DT}=$ culture Time/Population Doubling Number (PDN). $\mathrm{PDN}$ was calculated as the $\log \mathrm{NI} / \mathrm{N} 0 \times 3.31$ where $\mathrm{N} 0$ is the number of seeded cells and N1 the number of harvested cells.

Cell seeding on scaffold: Prior to use, PCL scaffolds were cut into pieces using a $4 \mathrm{~mm}$ biopsy punch and then sterilized by Ultraviolet (UV) irradiation. The PCL pieces were pre-wetted in DMEM for $12 \mathrm{~h}$ and then placed in 12 -well culture plates. Second passage chondrocytes, detached by trypsin/EDTA and condensed to a density of $5 \times 105 / 100 \mu \mathrm{L}$ were dropped on the PCL scaffolds to allow penetration of the cells. The cell/scaffold constructs were then incubated in $2 \mathrm{~mL}$ of DMEM containing $10 \%$ FBS for $24 \mathrm{~h}$. After this period, cells in the control group received DMEM containing $0.05 \%$ FBS and Mummy-treated groups received Mummy dissolved in DMEM at concentrations of 500 or $1000 \mu \mathrm{g} \mathrm{mL}^{-1}$ for $72 \mathrm{~h}$. After that, samples were prepared for evaluation of gene expression.

Real-time reverse transcription polymerase chain reaction (RT-PCR): The gene expression profile of type II collagen, Sox-9, aggrecan and cartilage oligomeric
Table 1: Primer sequences used in Real Time RT-PCR and related annealing temperature

\begin{tabular}{lll}
\hline Genes & Primers & $\begin{array}{l}\text { Annealing } \\
\text { temperature }\end{array}$ \\
\hline Sox9-F & AGAGAGGACCAACCAGAATTC & $57^{\circ} \mathrm{C}$ for $30(\mathrm{sec})$ \\
Sox9-R & TGGGTAATGCGCTTGGATAG & $57^{\circ} \mathrm{C}$ for 30 $(\mathrm{sec})$ \\
Coll2-F & GGCAATAGCAGGTTCACGTACA & $59^{\circ} \mathrm{C}$ for $30(\mathrm{sec})$ \\
Coll2-R & CGATAACAGTCTTGCCCCACTT & $59^{\circ} \mathrm{C}$ for $30(\mathrm{sec})$ \\
Comp-F & TGCAATGACACCATCCCAG & $56^{\circ} \mathrm{C}$ for $30(\mathrm{sec})$ \\
Comp-R & ACACACACTTTATTTGTCCTCTC & $56^{\circ} \mathrm{C}$ for $30(\mathrm{sec})$ \\
ACAN-F & CAACTACCCGGCCATCC & $56^{\circ} \mathrm{C}$ for $30(\mathrm{sec})$ \\
ACAN-R & GATGGCTCTGTAATGGAACAC & $56^{\circ} \mathrm{C}$ for 30 $(\mathrm{sec})$ \\
B actin-F & TCCTCCCTGGAGAAG AGC TA & $58^{\circ} \mathrm{C}$ for $45(\mathrm{sec})$ \\
B actin-R & TCA GGAGGA GCA ATG ATC TTG & $58^{\circ} \mathrm{C}$ for $45(\mathrm{sec})$ \\
\hline
\end{tabular}

Matrix Protein (COMP) of seeded chondrocytes on PCL scaffolds in both groups was analyzed using Real-time RT-PCR. The cell/scaffold constructs were ground in liquid nitrogen to powder. Total cellular RNA was extracted using RNX-PLUS reagent (Yekta Tajhiz kit). According to the manufacturer's protocol, chloroform was added to the samples placed on the ice and then centrifuged at 12,000 rpm for $15 \mathrm{~min}$. Then, isopropanol was added and samples were incubated at $-20^{\circ} \mathrm{C}$. After centrifugation, supernatant was discarded and $75 \%$ ethanol was added. Subsequently, samples were centrifuged at 7,500 rpm for $8 \mathrm{~min}$ and the pellet obtained was dissolved in DEPC-treated water. About $1000 \mathrm{ng} \mathrm{mL}^{-1}$ of total RNA was applied for cDNA synthesis using reverse transcription kit (Takara, RR037I, Japan). Real-time RT-PCR reactions were performed using a Corbett system (010755, Australia) with a SYBR Green master mix (Takara, RR820L, Japan). Different time and annealing temperatures for each gene are summarized in Table 1. The primer sequences are listed also in Table 1. The gene expression levels of chondrocytes in both treated and control groups were analyzed using the Pfaffl formula and $\beta$-actin used as internal control. All experiments were performed in triplicate.

Statistical analysis: Real-time RT-PCR data was analyzed with Graphpad software (Version 6). The results were reported as mean \pm standard deviation. Statistical difference between groups was determined by one-way ANOVA and Bonferroni post test. $\mathrm{p}<0.05$ was set as significant difference.

\section{RESULTS AND DISCUSSION}

Determination of effective mummy concentration: The effective concentration of mummy material on chondrocytes was assessed via. the MTT technique. Different concentrations of mummy $(200,500,1000$ and $2000 \mu \mathrm{g} \mathrm{mL}^{-1}$ ) were prepared by dissolving the material in DMEM culture medium. Figure 1 reveals the viability of chondrocytes treated with the different concentrations. 
The highest chondrocyte proliferation was found using $1000 \mu \mathrm{g} \mathrm{mL}^{-1}$ at 24,48 and $72 \mathrm{~h}$. Treatment with mummy at $500 \mu \mathrm{g} \mathrm{mL}^{-1}$ also resulted in similar proliferation rates, so, we evaluated the effects of mummy on chondrocytes at concentrations of 500 and $1000 \mu \mathrm{g} \mathrm{mL}^{-1}$ for $72 \mathrm{~h}$. Chondrocyte stimulation with higher dosages $\left(2000 \mu \mathrm{g} \mathrm{mL}^{-1}\right)$ resulted in cell toxicity and death.

Chemical analysis of mummy: It has been described previously by Dehghan and Faradonbeh ${ }^{[1]}$ that mummy contains of different ingredients as calcium ions, phosphate, carbonate, magnesium, nitrogen and also polysaccharides. To understand the other probable chemical components in this material, the GC-MS analysis technique was performed. As it can be understood from Fig. 2, no target compound was found in this material using GC-MS analysis. Unidentified peaks seen in this graph can be interpreted as impurities in solvent or noise of instruments.

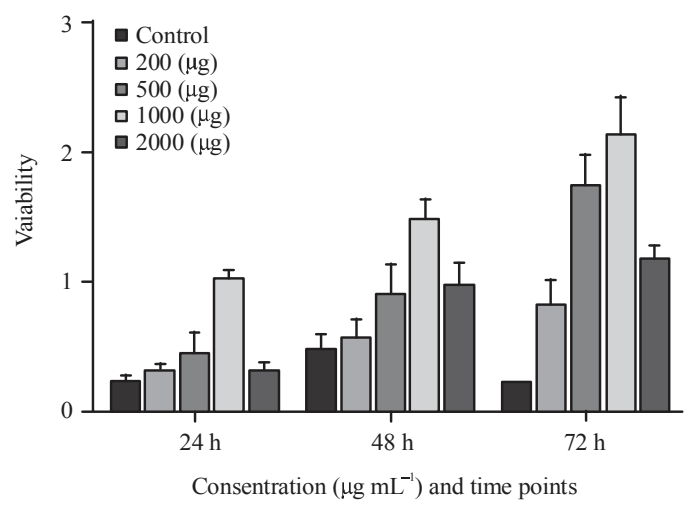

Fig. 1: Effects of different concentrations of mummy on chondrocyte proliferation and viability using the MTT assay technique
Doubling time: To evaluate the probable effect of mummy material on chondrocyte proliferation, doubling time determined. As can be seen in Fig. 3, treatment of chondrocytes with 500 and $100 \mu \mathrm{g} \mathrm{mL}^{-1}$ of Mummy resulted in increased proliferation compared to the control group $(\mathrm{p}<0.00001)$.

Effect of mummy material on chondrocyte gene expression: The effects of Mummy on cartilage ECM synthesis were evaluated through expression of collagen type II, aggrecan (ACAN), COMP and Sox-9 genes in both monolayer and 3D cultivated chondrocytes. As seen in Fig. 4a, the expression levels of COMP, Sox-9 and ACAN did not significantly increase in the presence of mummy at concentration of $500 \mu \mathrm{g} \mathrm{mL}^{-1}$ in monolayer chondrocytes. However, expression of collagen type II increased markedly compared to the chondrocytes in the control group $(\mathrm{p}<0.00001)$. Figure $4 \mathrm{a}$, also shows that in the presence of mummy at $1000 \mu \mathrm{g} \mathrm{mL}^{-1}$, the expression of COMP, Sox-9 and ACAN increased significantly in comparison to the control group but that of collagen type II did not.

In this study, we further evaluated the effects of mummy on the gene expression profile of chondrocytes seeded on the PCL scaffold. As seen in Fig. 4a, treatment of chondrocytes in 3D scaffolds with mummy $\left(500 \mu \mathrm{g} \mathrm{mL}^{-1}\right)$ did not increase expression of Sox-9, coll-2 and ACAN genes but COMP gene expression was increased significantly $(p<0.01)$ compared to the control cells. Treatment with mummy at $1000 \mu \mathrm{g} \mathrm{mL}^{-1}$ markedly increased levels of COMP, Sox-9 and ACAN but that of collagen II did not increase significantly. Compared to the monolayer cultured chondrocytes, the expression of COMP, Sox-9 and aggrecan genes was considerably higher in cells transferred to the 3D PCL scaffolds at the dosage of $1000 \mu \mathrm{g} \mathrm{mL} \mathrm{L}^{-1}$ of mummy but expression of collagen type II did not increase significantly (Fig. 4c). Expression of genes, except of collagen II, in the

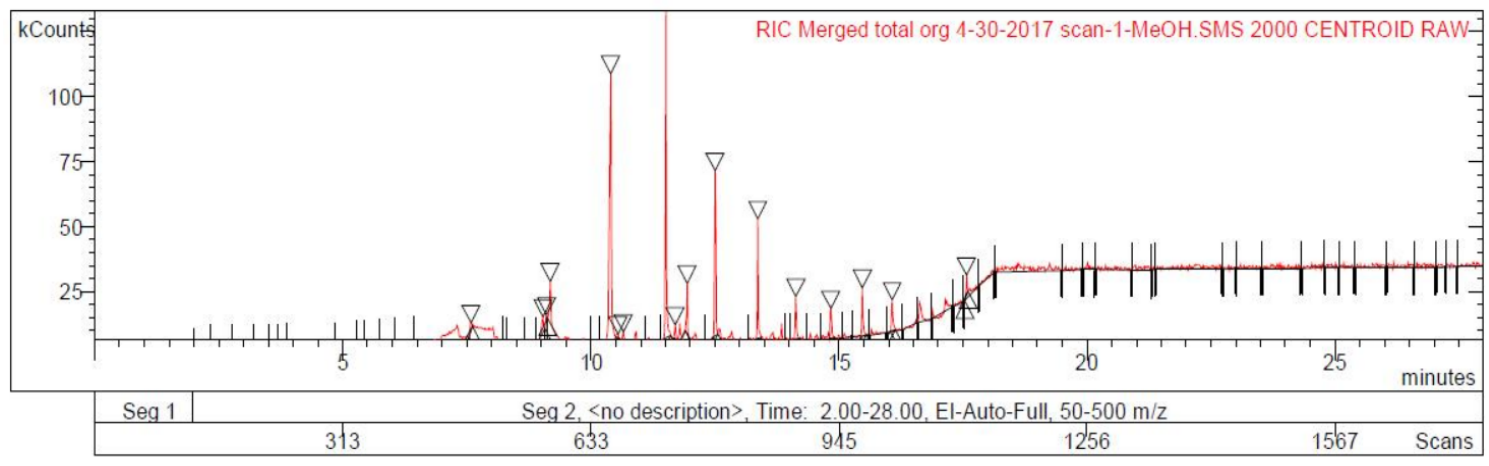

Fig. 2: Analysis of mummy ingredients by GC-MS technique. Irrelevant peaks can be related to impurities in applied solvent. No target compound found in mummy by this technique 
presence of $500 \mu \mathrm{g} \mathrm{mL}^{-1}$ of mummy was not different in monolayer chondrocytes when compared with $3 \mathrm{D}$ conditions.

In this study, we examined whether mummy material is able to accelerate the proliferation of chondrocytes and promote cartilage specific gene expression. This study resulted in the following results. Treatment of chondrocytes with mummy increased their proliferation rate, mummy at a concentration of $1000 \mu \mathrm{g} \mathrm{mL}-1$ significantly promoted the expression of collagen II, ACAN, COMP and Sox-9 genes in chondrocytes cultivated in both monolayer and 3D conditions and 3 the gene expression profile by chondrocytes seeded on PCL scaffolds was significantly higher compared to that in the monolayer cultivated cells.

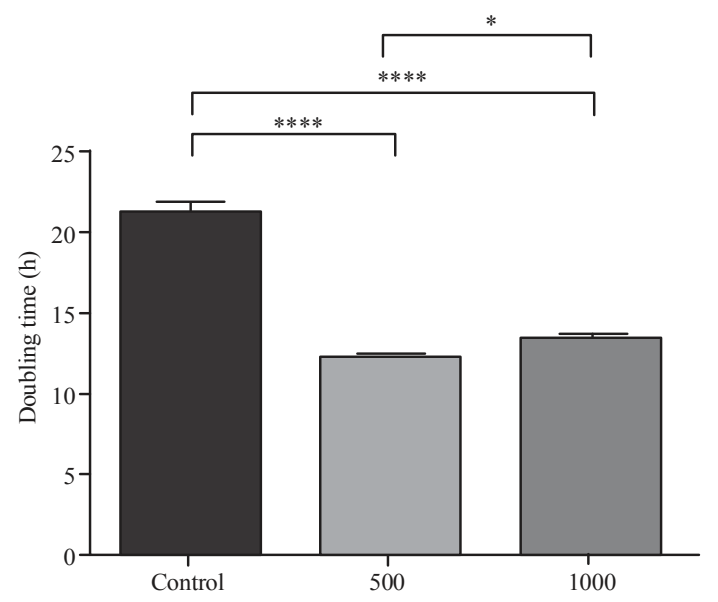

Fig. 3: Effect of mummy on the proliferation rate of chondrocytes $* \mathrm{p}<0.01, * * * * \mathrm{p}<0.00001$

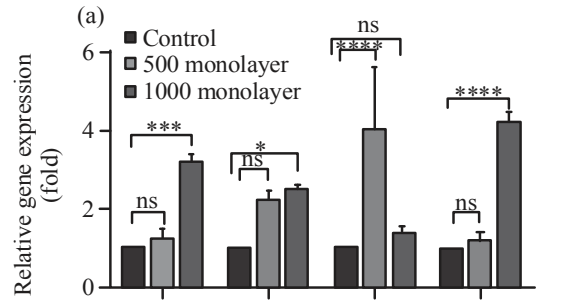

OA is the most common type of arthritis with unknown etiology that occurs due to an imbalance between synthesis and degradation of cartilage ECM and chondrocyte apoptosis ${ }^{[1,2]}$. Despite efforts in finding a safe and effective therapeutic method, current approaches are mostly palliative and cannot restore or maintain the original cartilage structure and function ${ }^{[6]}$. Thus, herbal medicines and nutraceuticals with less side effects and more potency are of growing interest to scientists and physicians. Our study revealed for the first time evidence that mummy has positive effects on cartilage metabolism. It has been shown that mummy significantly enhances chondrocyte proliferation and gene expression of collagen II, Sox-9, aggrecan and COMP. In Persian traditional medicine mummy has been advised for joint inflammation, bone fracture, wound healing and other related disorders for hundreds of years. Some pharmacological effects of this material such as anti-bacterial and anti-inflammatory enhancing collagen production at wound sites promoting healing of bone fracture ${ }^{[11]}$ and protecting the gastric mucosa against the ethanol-induced ulcer ${ }^{[13]}$ have been reported previously. The long history of mummy and its acceptance for safe use in Iran and some other Asian and African countries ${ }^{[13]}$ make it attractive for the evaluation of the effects of the material on chondrocytes.

In this study, we found that the addition of mummy to chondrocytes at concentrations ranging from $200-1000 \mu \mathrm{g} \mathrm{mL}^{-1}$ could promote their proliferation and the maximal concentration of this material with low cytotoxicity toward chondrocytes was achieved at $1000 \mu \mathrm{g} \mathrm{mL} \mathrm{m}^{-1}$. It has been described previously that regeneration of damaged articular cartilage is dependent

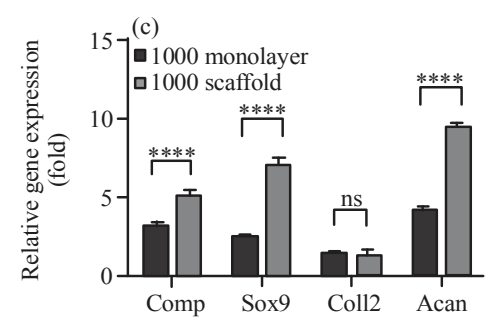

Fig. 4(a-c): Cartilage-specific gene expression analysis of mummy-treated chondrocytes cultured, (a) Monolayer, (b) 3D conditions and (c) Comparison between monolayer cultivated chondrocytes and cells seeded on 3D scaffolds. ${ }^{*} \mathrm{p}<0.01, * * * \mathrm{p}<0.0001$ and $* * * * \mathrm{p}<0.00001$ 
on chondrocyte proliferation which occurs at limited levels in osteoarthritic cartilage ${ }^{[15]}$. Hence, for restoration of impaired cartilage using tissue engineering in vitro expansion of chondrocytes is necessary. The results of our study suggest that mummy can be used as a factor to promote cell growth for engineered cartilage.

In this study, we also found that the expression of cartilage-specific genes including collagen type II, Aggrecan, COMP and Sox-9 was increased in chondrocytes treated with mummy in both monolayer and seeded on a scaffold. The Sox-9 gene has a crucial role during early chondrogenesis through mesenchymal cell commitment but also promotion of aggrecan and collagen II synthesis by mature chondrocytes ${ }^{[8]}$, for this reason, Sox-9 up-regulation is fundamental for cartilage formation. We found in this investigation that the expression of Sox-9 gene can be accelerated in mummy-treated chondrocytes cultured in both 2 and 3D environments. The upregulation of Sox-9 by mummy may also underping the increased expression of ECM components genes including collagen II, aggrecan and COMP.

The Extracellular Matrix in Cartilage (ECM) is predominantly composed of collagen type II, aggrecan and also COMP. Cartilage ECM entraps the chondrocytes and its composition is critical for the survival of these cells ${ }^{[16]}$. The ECM also modulates the homeostasis of cartilage and regenerates the damaged tissue by controlling the proliferation, adhesion and migration of chondrocytes $^{[17]}$.

In this study, we found that treatment of chondrocytes with mummy led to the upregulation of type II collagen, aggrecan and COMP. Collagen II is the major matrix protein in hyaline cartilage ${ }^{[18]}$ and together with other fibrils forms a highly elaborated network which is necessary for the appropriate function of this tissue ${ }^{[19]}$. Aggrecan is a type of proteoglycan that is capable of binding to hyaluronic acid and is crucial for the maintenance of the elastic feature of cartilage matrix ${ }^{[20,17]}$. Another structural element of the ECM with limited restoration capacity is Cartilage Oligomeric Protein (COMP) which is important for the integration of the cartilage tissue under stress conditions ${ }^{[20]}$. Degradation of above mentioned elements in the ECM of articular cartilage leads to degeneration of the structure and function of this tissue which is mostly irreversible because of the limited proliferative capacity of chondrocytes ${ }^{[21]}$. In this study, to critically assess the effect of mummy on chondrocytes, we also transferred the chondrocytes on to the PCL scaffolds and then treated them using mummy at dosages of 500 and $1000 \mu \mathrm{g} \mathrm{mL}^{-1}$. We demonstrated that Mummy treatment of chondrocytes cultured in 3D conditions (on PCL scaffolds) resulted in significantly higher expression of genes compared to that seen in monolayer cultured cells. Due to loss of the specific round phenotype of chondrocytes in monolayer conditions, it has been accepted widely that successful cell-based therapeutic methods for repair of articular cartilage lesions are dependent on the application of biodegradable and biocompatible scaffolds to mimic the natural hyaline cartilage 3D environment ${ }^{[22,23,8]}$.

In this study, we demonstrated that mummy can enhance gene expression of collagen II, aggrecan and COMP, so may be of relevance to efforts to prevent cartilage matrix degradation. Further extensive investigations are necessary to find the mechanisms underlying these effects of mummy material in chondrocytes.

\section{CONCLUSION}

In summary, the results of our study indicate that use of mummy can increase the proliferation of chondrocytes and up-regulate the expression of cartilage-specific genes. So, mummy may be introduced as a potent useful compound for cartilage tissue engineering.

\section{ACKNOWLEDGEMENTS}

This study is resulted from the research proposal leading to thesis of Fariba Rezaei, MSc student of Anatomical sciences and approved by Stem Cell Research center, Tabriz University of Medical sciences, Tabriz, Iran. The authors gratefully acknowledge the research deputy of Tabriz University of Medical Sciences for financial support and also our special thanks go to Dr. Mary Murphy in NUI Galway, Ireland for her kind contribution in editing the manuscript.

\section{REFERENCES}

01. Mobasheri, A., 2012. Intersection of inflammation and herbal medicine in the treatment of osteoarthritis. Curr. Rheumatol. Rep., 14: 604-616.

02. Chen, Y.J., K.S. Tsai, D.C. Chan, K.C. Lan and C.F. Chen et al., 2014. Honokiol, a low molecular weight natural product, prevents inflammatory response and cartilage matrix degradation in human osteoarthritis chondrocytes. J. Orthopaedic Res., 32: 573-580.

03. Hou, P.W., P.K. Fu, H.C. Hsu and C.L. Hsieh, 2015. Traditional Chinese medicine in patients with osteoarthritis of the knee. J. Traditional Complementary Med., 5: 182-196.

04. Nakagawa, Y., S. Mukai, S. Yamada, M. Matsuoka and E. Tarumi et al., 2014. Short-term effects of highly-bioavailable curcumin for treating knee osteoarthritis: A randomized, double-blind, placebo-controlled prospective study. J. Orthopaedic Sci., 19: 933-939. 
05. Montaseri, A., F. Busch, A. Mobasheri, C. Buhrmann and C. Aldinger et al., 2011. IGF-1 and PDGF-bb suppress IL-1ß-induced cartilage degradation through down-regulation of NF-?B signaling: Involvement of Src/PI-3K/AKT pathway. PLoS One, 6: 1-15.

06. Huh, J.E., B.K. Seo, Y.H. Baek, S. Lee and J.D. Lee et al., 2012. Standardized butanol fraction of WIN-34B suppresses cartilage destruction via inhibited production of matrix metalloproteinase and inflammatory mediator in osteoarthritis human cartilage explants culture and chondrocytes. BMC. Complementary Altern. Med., 12: 1-14.

07. Chung, C. and J.A. Burdick, 2008. Engineering cartilage tissue. Adv. Drug Deliv. Rev., 60: 243-262.

08. Li, D., T. Yuan, X. Zhang, Y. Xiao, R. Wang and Y. Fan, 2012. Icariin: A potential promoting compound for cartilage tissue engineering. Osteoarthritis Cartilage, 20: 1647-1656.

09. Uebersax, L., 2008. Silk fibroin scaffolding for growth factor delivery in tissue repair. Ph.D Thesis, ETH Library, Zurich, Switzerland.

10. Saraf, A. and A.G. Mikos, 2006. Gene delivery strategies for cartilage tissue engineering. Adv. Drug Delivery Rev., 58: 592-603.

11. Dehghan, M. and A.S. Faradonbeh, 2012. The effect of mummy on the healing of bone fractures. Afr. J. Pharm. Pharmacol., 6: 305-309.

12. Bartels, E.M., V.N. Folmer, H. Bliddal, R.D. Altman and C. Juhl et al., 2015. Efficacy and safety of ginger in osteoarthritis patients: A meta-analysis of randomized placebo-controlled trials. Osteoarthritis Cartilage, 23: 13-21.

13. Abshenas, J., R. Kheirandish and A.R. Salary, 2014. Gastroprotective effect of mummy on induced gastric ulcer in rats. Comp. Clin. Pathol., 23: 305-309.

14. Cheleschi, S., N.A. Pascarelli, G. Valacchi, A. Di Capua and M. Biava et al., 2015. Chondroprotective effect of three different classes of anti-inflammatory agents on human osteoarthritic chondrocytes exposed to IL-1ß. Intl. Immunopharmacol., 28: 794-801.
15. Wu, J., X. Liu, C.O. Chan, D.K. Mok and S.W. Chan et al., 2014. Petroleum ether extractive of the hips of Rosa multiflora ameliorates collagen-induced arthritis in rats. J. Ethnopharmacol., 157: 45-54.

16. Villanueva, I., S.K. Gladem, J. Kessler and S.J. Bryant, 2010. Dynamic loading stimulates chondrocyte biosynthesis when encapsulated in charged hydrogels prepared from poly (Ethylene glycol) and chondroitin sulfate. Matrix Biol., 29: 51-62.

17. Zhang, L., X. Zhang, K.F. Li, D.X. Li and Y.M. Xiao et al., 2012. Icariin promotes extracellular matrix synthesis and gene expression of chondrocytes In vitro. Phytother. Res., 26: 1385-1392.

18. Shafaei, H., E. Esfandiari, A. Esmaeili, S. Razavi and B. Hashemibeni et al., 2013. Optimizing a novel method for low intensity ultrasound in chondrogenesis induction. Adv. Biomed. Res., 2: $1-10$

19. Aszodi, A., E.B. Hunziker, B.R. Olsen and R. Fassler, 2001. The role of collagen II and cartilage fibril-associated molecules in skeletal development. Osteoarthritis Cartilage, 9: 150-159.

20. Gomez-Barrena, E., L. Lindroos, A. Ceponis, M. Lopez-Franco and O. Sanchez-Pernaute et al., 2006. Cartilage Oligomeric Matrix Protein (COMP) is modified by intra-articular liposomal clodronate in an experimental model of arthritis. Clin. Exp. Rheumatol., 24: 622-628.

21. Hara, E.S., M. Ono, S. Kubota, W. Sonoyama and Y. Oida et al., 2013. Novel chondrogenic and chondroprotective effects of the natural compound harmine. Biochim., 95: 374-381.

22. Montaseri, A., L. Roshangar, J.S. Rad, H. Shafaei and M. Shakibaei et al., 2012. Formation of repaired hyaline cartilage using PDGF-treated chondrocyte/PCL construct in rabbit knee articular cartilage defect. Ann. Biol. Res., 3: 1975-19874.

23. Schulze-Tanzil, G., 2009. Activation and dedifferentiation of chondrocytes: Implications in cartilage injury and repair. Ann. Anat. Anatomischer Anz., 191: 325-338. 